九州大学学術情報リポジトリ

Kyushu University Institutional Repository

\title{
Effect of Various Compounds on the Activity of Laccases from Basidiomycetes and Their 0xidative and Demethoxylating Activities
}

Cho, Nam-Seok

School of Forest Resources and Rural Engineering, Chungbuk National University

Kim, Dong-Hun

School of Forest Resources and Rural Engineering, Chungbuk National University

Cho, Hee-Yeon

Dental Research Institute, School of density, UCLA

Ohga, Shoji

Department of Forest and Forest Products Sciences, Kyushu University

他

https://doi.org/10.5109/9231

出版情報: 九州大学大学院農学研究院紀要. 51 (2)，pp.211-218，2006-10-27. Faculty of Agriculture, Kyushu University

バージョン :

権利関係 : 


\title{
Effect of Various Compounds on the Activity of Laccases from Basidiomycetes and Their Oxidative and Demethoxylating Activities
}

\author{
Nam-Seok CHO ${ }^{1}$, Dong-Hun KIM ${ }^{1}$, Hee-Yeon $\mathrm{CHO}^{2}$, Shoji OHGA* \\ and Andrzej LEONOWICZ ${ }^{3}$ \\ Laboratory of Forest Resources Management, Division of Forest Ecosphere Management, \\ Department of Forest and Forest Products Sciences, Kyushu University, \\ Sasaguri, Fukuoka 811-2415, Japan \\ (Received May 30, 2006 and accepted July 24, 2006)
}

\begin{abstract}
Selected species of Basidiomycetes (Abortiporus biennis, Cerrena unicolor and Trametes versicolor) were known to produce enhanced extracellular laccase (benzenediol:oxygen oxidoreductase, EC 1.10.3.2) when they exposed to some heavy metal ions, xenobiotics and lignin related compounds. The constitutive and inducible forms of purified laccase showed oxidative and demethoxylating activities, which prove the bifunctionality of the enzyme. The oxidative/demethoxylating ratios in inducible laccases varied depending on used inducers. The demethoxylating activities of laccases induced by lignin related compounds were much higher than those induced by various xenobiotic substances.
\end{abstract}

\section{INTRODUCTION}

Living organisms are subject to different kind of stresses, such as change in the temperature, UV radiation and appearance of various xenobiotic compounds in the environment (Jamieson, 1995). Some of these hazardous determinants are called reactive oxygen species, which are generated during the normal cellular metabolism in living organisms. They can also appear in the presence of pro-oxidants such as hydrogen peroxide, menadione or paraquat in the culture medium. When the level of oxidants increases beyond antioxidants capacity of the cell-it termed as oxidative-stress conditions (Jamieson, 1995). Consequently the organisms have developed during their evolution a range of effective enzymatic or non-enzymatic systems of response to stress factors (Jamieson, 1995). Basidiomycetes species, used in the present study, are considered to be a very interesting but little known in this respect. Given their exceptional adoption abilities to accommodate the detrimental conditions of the environment, where they continue to act as natural lignocellulose degraders (Tuor et $a l ., 1995)$. Our experiments imply a distinct influence on various stress factors exerted upon the activity of laccase, the oxidoreductase mediated lignin depolymerization (Thurston, 1994; Collins and Dobson, 1997; Leonowicz et al., 2001).

The laccase ( $p$-diphenol: oxygen oxidoreductase; EC 1.10.3.2) is a copper-containing enzyme that catalyses the oxidation of a phenolic substrate by coupling it to the reduction of oxygen to water. The enzyme, belonging to polyphenolic oxidases display a wide range

\footnotetext{
School of Forest Resources and Rural Engineering, Chungbuk National University, Cheongju 361-763, Korea

${ }^{2}$ Dental Research Institute, School of Dentistry, UCLA, LA, California 90095, USA

${ }^{3}$ Department of Biochemistry, Marie Curie-Sklodowska University, Lublin 20-031, Poland

* Corresponding author (E-mail: ohgasfor@mbox.nc.kyushu-u. ac.jp)
}

of substrates, catalyses the polymerization, depolymerization, and demethylation/demethoxylation of phenolic compounds (Leonowicz et al., 2001). Fungal laccase is also known to use in biotechnological processes, viz., bleaching (whitening) wood pulp, decomposition of different kinds of bio-polymers and detoxification of environmental pollutants (Monteiro and Carvalho, 1998; D'Annibale et al., 1999; Cho et al., 1999a; Cho et al., 1999b). Laccase oxidizes a number of aromatic hydrogen donors forming free phenoxy radicals and catalyses reactions of decarboxylation and demethoxylation of phenolic and methoxyphenolic acids (Thurston, 1994; Potthast et al., 1995; Leonowicz et al., 2001). Laccases are produced by the majority of white-rot fungi, also by other types of fungi and by plants (Aramayo and Timberlake, 1990; Wahleithner et al., 1996). There are many reports that a number of substances have influences on the activity of the extracellular laccase in various white-rot fungi. For example extracellular laccase of Botrytis cinerea has been induced by gallic acid (Gigi et al., 1980), Neurospora crassa one by cycloheximide (Froehner and Eriksson, 1974), Phanerochaete chrysosporium by $\mathrm{CuSO}_{4}$ (Dittmer et al., 1997), Pleurotus eryngii by alkali lignin, vanillic acid and veratric acid (Munoz et al., 1997), Pycnoporus cinnabarinus by lignosulfonic acid, veratryl alcohol and 2,5-xylidine, and Trametes versiolor laccase by $\mathrm{CuSO}_{4}, \mathrm{NH}_{4}{ }^{+}$, 1-hydroxybenzotriazole (Collins and Dobson, 1997) and 2,5-xylidine (Bollag and Leonowicz, 1984). These studies indicated that fungal laccase could be induced by several inorganic and organic substances. To enlight more information on inducible laccases and its production by various inducers, such as divalent cations, selected pro-oxidants and aromatic compounds including Björkman's lignin and lignosulfonate, this study was performed their oxidative and demethoxylating activities in comparison with analogical activities of constitutive laccases. 


\section{MATERIALS AND METHODS}

\section{Fungal strains and culture conditions}

All fungal species used in this study (Table 1) were maintained on $2 \%(\mathrm{wt} / \mathrm{v})$ malt agar slants. The media containing sucrose (C source), $L$-asparagine ( $\mathrm{N}$ source) and trace element's solution, inoculated with ca. $0.5 \mathrm{~cm}^{2}$ agar plugs of fungi (Leonowicz et al., 1984). The cultures were grown in static flask at $25^{\circ} \mathrm{C}$ till the mycelium forming a mat on surface of the liquid. The mycelial mats were collected and homogenized in a Warring Blender. The shallow stationary cultures, after inoculation with $4 \%(\mathrm{v} / \mathrm{v})$ of the homogenate, were incubated at $25^{\circ} \mathrm{C}$ in Erlenmayer flasks containing the basal medium. The extracellular medium was separated from mycelium by filtration through Miracloth (Calbiochem). All measurements were recorded using extracellular cultures at the peak of laccase activity after addition of inducing substance. An excess sugar in the liquid medium eliminated the spontaneous induction of laccase (Bollag and Leonowicz, 1984). This sugar rich medium without inducers for laccase activity, allowed the production of constitutive laccase by fungi, whereas the biosynthesis of the induced enzyme was repressed by sugar (Vasdev and Kuhad, 1994, Manzanares et al., 1995). The results shown in Table 1 indicated that $A$. biennis and $T$. versicolor, and especially $C$. unicolor were best producers of laccase. Therefore these three strains were used in further experiments

\section{Stress conditions}

The 10-day-old cultures of A. biennis, C. unicolor, and $T$. versicolor were treated with different kinds of divalent cations, such as $\mathrm{Cd}(\mathrm{II}), \mathrm{Cu}$ (II), $\mathrm{Zn}$ (II) and Mn(II) ions (25 $\mathrm{mg} \mathrm{l}^{-1}$ ), selected pro-oxidants like $\mathrm{H}_{2} \mathrm{O}_{2}$, menadione, paraquat (0.25 $\mathrm{mM}$ each) and saponin $\left(25 \mathrm{mg} \mathrm{l}^{-1}\right)$, and methoxyphenolic compounds (0.2 mM each). Björkman's lignin was dissolved in 5\% (w/w) dimethylsulfoxide (DMSO) and mixed with growing medium to give a final concentration of $100 \mathrm{mg} \mathrm{l}^{-1}$. The final concentration of added high molecular fraction of lignosulfonate (Leonowicz et al., 2000) was also $100 \mathrm{mg} 1^{-1}$ of growing medium.

\section{Laccase assays}

Laccase activity was measured by monitoring the oxidation of syringaldazine at $\mathrm{A}_{520}$ with using molar absorption coefficient $\mathrm{E}=65,000 \mathrm{M}^{-1} \mathrm{~cm}^{-1}$ (Leonowicz and Grzywnowicz, 1981) at pH optimum for particular fungi, but with morpholineethanesulfonic acid buffer replaced by $0.1 \mathrm{M}$ McIlvaine (1921) citrate-phosphate buffer (Bollag and Leonowicz, 1984). The reaction mixture contained $0.025 \mathrm{mM}$ syringaldazine, $50 \mathrm{mM}$ citrate-phosphate buffer pH 5.2 and enzyme. To exclude endogenous peroxide, the $10 \mathrm{~min}$. preincubation (stirring) of the enzyme with catalase $\left(10 \mathrm{mg} \mathrm{ml}^{-1}\right)$ was performed. The laccase activity was calculated in nkat/litre. The distinction of laccase forms (either constitutive or inducible) based on polyacrylamide gel electrophoresis was performed (Leonowicz et al., 1978).

\section{Polyacrylamide-gel electrophoresis}

Electrophoresis was performed in the Tris/borate system, pH 8.45, protein bands were visualized with Coomassie Brilliant Blue R-250, and laccase, after adjustment of $\mathrm{pH}$ in the gels to 4.5 , by the reaction with p-phenylenediamine (Leonowicz et al., 1978).

\section{Isolation and purification of constitutive laccase}

For the purification of constitutive laccases from $A$. biennis, C. unicolor and $T$. versicolor, method of Gianfreda et al. (1998) with some our modifications was followed. The constitutive laccase forms were selected using of polyacrylamide gel electrophoresis (Leonowicz et al., 1978). The aerated cultures at the peaks of laccase activity were filtered through Miracloth (Calbiochem, Lucerne, Switzerland). Each filtrate was desalted on the Sephadex G-25 column. The enzyme

Table 1. Fungal strains, their origin and laccase activity

\begin{tabular}{rlrr}
\hline FCL No.* & \multicolumn{1}{c}{ Species } & Origin & Laccase activity (nkat/l) \\
\hline 123 & Abortiporus biennis (Bull.ex Fr.) Sing. & MC T 060; & 2193 \\
139 & Cerrena unicolor (Bull.ex Fr.) Murr. & MC T 143; & 45276 \\
124 & Gleophyllum odoratum (Wulf.ex Fr.) Imaz. & MC T 062; & FPD 5042; \\
19 & Inonotus obliquus (Pers.ex Fr.) Pil. & ACTT 44307 & 1870 \\
67 & Pholiota mutabilis (Sch.ex Fr.) Murril. & AMD 64; & 1130 \\
39 & Lentinus lepideus Fr. & ACTT 64658; & 0 \\
99 & Phlebia radiata Fr. & ACTT 44309; & 170 \\
13 & Pleurotus ostreatus (Jacq.ex Fr.) Kumm. & BCTUA 104; & 1690 \\
237 & Pleurotus sajor-caju & FPD 4838; & 1987 \\
5 & Serpula lacrimans (Wulf.ex Fr.) Schreet. & & 2235 \\
& Trametes versicolor (L.ex Fr.) Pil. & &
\end{tabular}

* No. in the Fungal Collection of Lublin registered as FCL in Information Center for European Culture Collections, Braunschweig, Germany. MC: Molitoris Collection, Institute of Botany, University of Regensburg, Germany; FPD: Department of Forest Pathology, Academy of Agriculture, Cracow, Poland; AMD: Department of Agricultural Microbiology, Academy of Agriculture, Cracow, Poland; ACTT: American Type Culture Collection, Rockville, Md., USA; FCTUA: Laboratory of Forest Product Chemistry, Tokyo University of Agriculture, Tokyo, Japan; BIAU: Institute of Botany, Ernst-Moritz-Arndt University, Greifswald, Germany; FPD: Department of Forest Pathology, Academy of Agriculture, Cracow, Poland. 
solutions were concentrated to ca. one tenth of the volume at $4{ }^{\circ} \mathrm{C}$ with an Amicon ultrafiltration system equipped with a filter type PTGC (pore size 10,000 NMWL) and dialyzed 7 times to the deionized water and (before the end of dialysis) to $0.1 \mathrm{M}$ phosphate buffer, pH 6 . Then $25 \mathrm{ml}$ portions of enzymes were applied onto the ConA-Sepharose columns $(7 \times 1.5 \mathrm{~cm})$, which were then washed with $0.1 \mathrm{M}$ phosphate buffer, until all unbound proteins were removed. The specifically bound proteins, including laccase, were eluted from the column with $20 \%$ sucrose in $0.1 \mathrm{M}$ phosphate buffer, $\mathrm{pH}$ 6. The fractions showing the highest laccase activity were concentrated by ultrafiltration, poured onto DEAE-Toyopearl column $(25 \times 1.5 \mathrm{~cm})$ and eluted by a linear gradient of $0-0.35 \mathrm{M} \mathrm{NaCl}$ in $5 \mathrm{mM}$ Tris/HCl buffer, $\mathrm{pH}$ 6.0. The fractions around the top of laccase activity, eluted by $\mathrm{NaCl}$ were collected, dialyzed to $0.5 \mathrm{mM}$ Tris/HCl buffer, $\mathrm{pH} 6$ and applied onto a column of AH-sepharose 4B coupled to syringaldehyde. The enzyme was eluted by $0.5 \mathrm{M}$ ammonium sulfate dissolved in the same buffer, $\mathrm{pH}$ 6.0, and stored as freeze-dried. The degrees of purification were about 67, 49 and 72-folds for A. biennis, C. unicolor and T. versicolor, respectively.

\section{Isolation and purification of induced laccase}

Cultures of $A$. biennis, $C$. unicolor and T. versicolor were incubated at $28^{\circ} \mathrm{C}$ according to Fahraeus and Reinhammar (1967) with modification of Rogalski et al. (1990) and filtered through Miracloth. Inducers were added to the 10-day old cultures at the initial concentration as was described in the "Stress conditions". The induced forms were selected by polyacrylamide gel electrophoresis (Leonowicz et al., 1978). Isolation and preliminary purification of inducible laccases at the peak of enzyme activity was performed by chromatography on the Sephadex G-50 and DEAE-Sephadex A-50 columns (Leonowicz et al., 1978). The enzymes were further concentrated with the Amicon system, dialyzed, applied onto the ConA-Sepharose columns, eluted with sucrose, concentrated by ultrafiltration, poured onto DEAE-Toyopearl column eluted with $\mathrm{NaCl}$, applied onto a column of AH-sepharose 4B coupled to syringaldehyde, eluted with ammonium sulfate, and stored as freeze-dried in $0.1 \mathrm{M}$ phosphate buffer $\mathrm{pH}$ 6. The degrees of purification were about 79, 57 and 93-folds for A. biennis, C. unicolor and T. versicolor, respectively.

\section{Determination of protein}

Protein concentrations were determined by using Bradford reagent and bovine serum albumin used for the standards (Bradford, 1976).

\section{Determination of demethoxylating and oxidative activities of laccase}

Syringic acid (20 $\mu \mathrm{mol})$ was added to $4 \mathrm{ml}$ of $1 \mathrm{mM}$ acetate buffer $\mathrm{pH} 4.0$ or containing laccase (250 $\mu \mathrm{g}$ ), the volumes was adjusted to $5 \mathrm{ml}$ with the same buffer, respectively, and the sample was incubated for $3 \mathrm{~h}$ at $30^{\circ} \mathrm{C}$. The released methanol was distilled off (Ishihara and Miyazaki, 1974) and its content in the distillate was determined using chromotropic acid (Adler and Hernestam, 1955). Simultaneously, after evaporation of the reaction mixtures at $40^{\circ} \mathrm{C}$ under vacuum to dryness, the degree of demethoxylation was determined by measuring the content of methoxyl groups non-dissociated from the aromatic rings of the substrates; the assay was performed with hydroiodic acid according to Brauns (1952) with the modification of Leonowicz (1965). The oxidative activity of laccase was determined polarographically (Leonowicz et al., 1979).

\section{Chemicals}

All chemicals were reagent grade quality. Bovine liver catalase was from Aldrich-Chemie (Steinheim, Germany). AH-Sepharose 4B, ConA-Sepharose and Sephadex G-25 were from Pharmacia (Uppsala, Sweden); DEAE Toyopearl $650 \mathrm{~S}$ was from Tosoch Corporation (Tokyo, Japan); acrylamide and N,N'-methylene-bis-acrylamide were from B.D.H. (Poole, England) and Coomassie Brilliant Blue R-250 was from Serva (Heidelberg, Germany). Björkman's lignin was isolated from rye straw and prepared according to the method of Björkman (1954 and 1957) with the modification of Trojanowski and Leonowicz (1963). The high molecular fraction of lignosulfonate (MW 74,000) was prepared according to Leonowicz et al. (1985).

\section{RESULTS AND DISCUSSION}

Laccase is known as multiple and extracellular enzymes which occur in basidiomycete fungi in nature. The enzyme can be stimulated or induced by copper, a number of organic compounds and temperature shocks. Stimulation of the enzyme by copper in fungal cultures was reported by Salas et al. (1995) and Mansur et al. (1997), and by temperature shocks by Fink-Boots et al. (1999). Laccase induction by copper was described by Edens et al. (1999), Farnet et al. (1999), Palmieri et al. (2000) and Klonowska et al. (2001), by lignin by Trojanowski and Leonowicz (1969), and by lignin related compounds by Leonowicz and Trojanowski (1975), Leonowicz et al. (1978), Leonowicz and Malinowska (1982), Bollag and Leonowicz (1984), Munoz et al. (1997), Edens et al. (1999), Farnet et al. (1999) and Klonowska et al. (2001).

The appearance of laccase from basidiomycetes as constitutive and inducible forms was reported by Leonowicz and Trojanowski (1975), Leonowicz et al. (1978), Leonowicz and Malinowska (1982), Bollag and Leonowicz (1984), Munoz et al. (1997), Edens et al. (1999), Farnet et al. (1999), Farnet et al. (2000) and Klonowska et al. (2001). Mansur et al. (1998) found three laccase genes in basidomycete fungus I-62 (CECT 20197). Among them one was non-induced, and the other induced by veratryl alcohol. Much earlier the appearance of laccase coding mRNA was reported for inducible laccases in three fungal strains, Coriolus versicolor, Pleurotus ostreatus and Pholiota muta- 
bilis, induced by ferulic acid (Leonowicz et al., 1972; Leonowicz and Trojanowski, 1978). This study discussed unusual activity of purified constitutive and inducible laccases from the three species of white-rot Basidiomycetes.

\section{Induction of laccase by divalent cations}

A. biennis, $C$. unicolor and $T$. versicolor cultures were grown in liquid mineral media and subjected to different divalent cations. The stimulating effect of cations on laccase activity of growing cultures is presented in Table 2 . These results provide unequivocal evidence for significant stimulation the activity of extracellular laccase in comparison with the controls. The increased laccase level initiated at high temperature (Fink-Boots et al., 1999) in the cultures of selected strains of Basidiomycetes, as a consequence of adaptation to changes in environmental temperature conditions. The removal of heavy metals from aqueous solutions by white-rot fungi was reported by Jarosz-Wilkolazka et al. (2001). The enhanced activity of laccase due to heavy metals at higher concentration, may elucidate this enzyme involvement in fungal adaptation process, so this technology could be used for metal containing waste materials.

Table 2. Effect of various divalent cations on the laccase activity

\begin{tabular}{cccc}
\hline \multirow{2}{*}{$\begin{array}{c}\text { Heavy metal } \\
\text { cation }\end{array}$} & \multicolumn{3}{c}{ Laccase induction, \% } \\
\cline { 2 - 4 } & A. biennis & C. unicolor & T. versicolor \\
\hline $\mathrm{Cd}^{+2}$ & 1450 & 1530 & 580 \\
$\mathrm{Cu}^{+2}$ & 670 & 545 & 740 \\
$\mathrm{Mn}^{+2}$ & 22 & 113 & 210 \\
$\mathrm{Zn}^{+2}$ & 380 & 290 & 820 \\
\hline
\end{tabular}

* The cations were added to 10-day-old cultures. The activity was measured in sugar-rich culture at the peak of the enzyme level. Data present activities of laccase in the induced cultures in comparison to the controls taken as $100 \%$. All data represent mean of triplicate measurements (sample deviations $\leq 10 \%$ ).

Table 3. Effect of various xenobiotic inducers on the laccase activity

\begin{tabular}{lccc}
\hline \multirow{2}{*}{ Xenobiotics } & \multicolumn{3}{c}{ Laccase induction, \% } \\
\cline { 2 - 4 } & A. biennis & C. unicolor & T. versicolor \\
\hline $\mathrm{H}_{2} \mathrm{O}_{2}$ & 610 & 413 & 390 \\
Menadione & 850 & 730 & 1020 \\
Paraquat & 490 & 320 & 790 \\
Saponins & 420 & 740 & 1210 \\
\hline
\end{tabular}

* The inducers were added to 10-day-old cultures. The activity was measured in sugar-rich culture at the peak of the enzyme level. Data present activities of laccase in the induced cultures in comparison to the control ones taken as $100 \%$. All data represent mean of triplicate measurements (sample deviations $\leq 10 \%$ ).

\section{Induction by oxidative stress factors}

A notable increase in laccase activity had appeared in the cultures following the treatment with oxidative stress factors, $\mathrm{H}_{2} \mathrm{O}_{2}$, menadione and paraquat and saponin (Table 3). In addition, we applied another inducers, namely lignin and its low molecular derivatives.

\section{Induction by lignin derivatives and aromatic compounds}

As shown in Table 4, the induced laccase activity from $T$. versicolor by lignin and its derivatives was higher than those from $A$. biennis and C. unicolor. Three compounds, ferulic acid, syringic acid and sinapic acid, showed the highest inducibility of laccase, while the other compounds induced the enzyme to a lower extent. Among examined compounds, higher inducing effect was shown by acids than their corresponding aldehydes (Table 4).

Table 4. Effect of lignin derivatives and aromatic compounds on the laccase activity

\begin{tabular}{lrrr}
\hline \multirow{2}{*}{ Inducer } & \multicolumn{3}{c}{ Laccase induction, \% } \\
\cline { 2 - 5 } A. biennis & C. unicolor & T. versicolor \\
\hline Lignin preparations: & & & \\
Björkman's lignin & 254 & 29 & 2278 \\
Lignosulfonate & 295 & 32 & 2345 \\
& & & \\
Aromatic substances: & & & \\
Chlorogenic acid & 348 & 15 & 1194 \\
Coniferyl alcohol & 50 & 3 & 172 \\
Gallic acid & 246 & 10 & 844 \\
Guaiacol & 14 & 1 & 49 \\
Caffeic acid & 424 & 18 & 1469 \\
Ferulic acid & 970 & 41 & 3324 \\
Orcinol & 9 & 1 & 29 \\
Protocatechuic acid & 408 & 17 & 1397 \\
Sinapic acid & 711 & 30 & 2436 \\
Syringic acid & 650 & 37 & 3430 \\
Syringaldehyde & 441 & 19 & 1511 \\
Vanillic acid & 311 & 13 & 1067 \\
Vanillin & 196 & 8 & 672 \\
Veratraldehyde & 102 & 4 & 348 \\
Veratric acid & 143 & 6 & 491 \\
\hline
\end{tabular}

* The compounds were added to 10-day-old cultures. The activity was measured in sugar-rich culture at the top of the enzyme level. Data present activities of laccase in the indced cultures in comparison to the control ones taken as $100 \%$. All data represent mean of triplicate measurements (sample deviations $\leq 10 \%$ ).

\section{Purification}

Laccases were purified from the culture filtrates of three fungal strains as described in Materials and Methods. By DEAE-Sephadex A-50 column chromatography the inducible laccase was separated from the constitutive ones and purified further by consecutive steps up to $\mathrm{AH}$-sepharose 4B coupled to syringaldehyde column (Fig. 1). In the case of all three fungal strains one constitutive and one induced form appeared (Fig. 
$(-)$

$(+)$

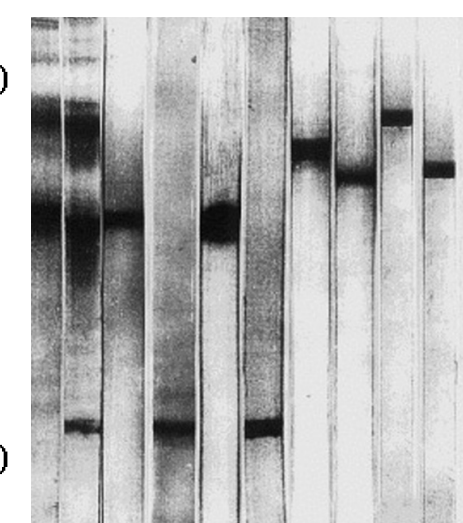

$\begin{array}{llllllllll}A & B & C & D & E & F & G & H & \text { I } & J\end{array}$

Fig. 1. Polyacrylamide gel electrophoresis of laccases from $A$. biennis, C. unicolor and T. versicolor. Extracellular fluid of A.biennis culture (gel A); extracellular fluid of $A$. biennis culture induced by ferulic acid (B); purified laccase protein from extracellular fluid of $A$. biennis culture (C); purified laccase protein from extracellular fluid of $A$. biennis culture induced by ferulic acid (D); purified laccase activity from extracellular fluid of $A$. biennis culture (E); purified laccase activity from extracellular fluid of A. biennis culture induced by ferulic acid (F); purified laccase activity from extracellular fluid of C. unicolor culture (G); purified laccase activity from extracellular fluid of C. unicolor culture induced by ferulic acid $(\mathrm{H})$; purified laccase activity from extracellular fluid of $T$. versicolor culture (I); purified laccase activity from extracellular fluid of $T$. versicolor culture induced by ferulic acid $(J)$. For details see Materials and Methods.

1). In the case of mostly investigated Trametes species, it is in agreement with the earlier reports: only one constitutive form appeared in non-induced culture (Hofer and Schlosser, 1999) and two in the cultures induced by various inducers, such as 2,5-xylidine (Bollag and Leonowicz, 1984; Rogalski et al., 1990), ferulic acid (Leonowicz et al., 1978), and green tea extract (Motoda, 1999). Some other fungi showed also one constitutive and one inducible form e.g. Fomes annosus and Pholiota mutabilis, whereas Pleurotus ostreatus produced even five constitutive forms and one inducible (Bollag and Leonowicz, 1984). In this report we described appearance of laccases in the cultures of $A$. biennis and $C$. unicolor. Laccases from the cultures of T. versicolor serves as reference.

\section{Polyacrylamide gel electrophoresis}

When any inducer was omitted, laccase was the only one laccase band (constitutive form) detected in the extracellular fluid or purified laccase of three strains of fungi (Fig. 1, gel A and $\mathrm{C}$ for $A$. biennis, gel $\mathrm{G}$ for $C$. unicolor and I for $T$. versicolor). In the presence of any inducer, a second one band (inducible form) was detected in the gels (Fig. 1, gel B and D for A. biennis, gel $\mathrm{G}$ for $C$. unicolor and J for T. versicolor). This patterns were reproducible for each experiment. The appearance in the gel only one band of the enzyme (constitutive or induced) reported also Farnet et al. (2000) for laccase of Marasmius quercophilus 17. In our case the constitutive and inducible forms were in the gels separated. Also Klonowska et al. (2001) reported that the constitutive and inducible forms of laccase of Marasmius quercophilus C30 appeared in the gels as separated spots. Patterns obtained in the absence or the presence of any inducer were very similar, which means the "inducible" bands reached the same position in the gels that in the case of all inducers tested in the strains investigated (Fig. 1).

The similar phenomenon reported Klonowska et al. (2001) for M. quercophilus C30 laccase induced either by copper or by $p$-hydroxybenzoic acid. In this case, however, the constitutive and inducible forms appeared in the gels as the separated spots (Klonowska et al., 2001). The appearance of different forms of laccase in the same strain (like in $M$. quercophilus 17 and $M$. quercophilus C30) is possible depends on strain source (Farnet et al., 2000).

\section{Oxidative and demethoxylating activities of the laccases}

All results presented up to now unequivocally showed that laccase could be induced by various inorganic and organic compounds. In order to know the substrate specificity of obtained laccases, the oxidative and demethoxylating activities of particular inducible laccases were discussed in comparison to constitutive ones. From Table 5 it was clear that the oxidative activity of inducible laccases was about three times as high as that of the constitutive forms. This is in agreement with our earlier observations on the different properties of the inducible and constitutive laccases with respect to molecular weight, electrophoretic mobility, chromatographic behaviour (Leonowicz and Trojanowski, 1975) and oxidative/demethoxylating specificity (Leonowicz et al., 1979; Leonowicz et al., 2000). But according to present results (Table 5), the demethoxylating activity of inducible laccases is differentiated depending on used inducers. The laccase enzymes induced by lignin and its low molecular derivatives were shown much higher activity than those induced by cadmium, menadione, or other xenobiotics (Table 3). Similarly in nature, the fungi attacking wood may use their inducible laccase forms for lignin degradation through demethoxylating process, and these inducible laccases could produce lignin and its derivatives in wood. It is of considerable interest that the amounts of methanol released by demethoxylation of lignin and related substances correspond to the decrease in methoxyl groups in the reaction media (Table 5). This confirms our earlier results obtained by using of $P$. mutabilis laccase (Leonowicz et al., 1979). The demethylating/demethoxylating processes seem to be of basic significance in lignin degradation (Leonowicz et al., 1991; Leonowicz et al., 2001). The polymerization/depolymerization activities of laccase can result from the oxidative ability of the enzyme toward phenols or polyphenols, formed radicals would be reacted each other, and causing both demethylating/demethoxylating processes. Such phenolic substances could be produced in the course of demethoxy- 
Table 5. Oxidative and demethoxylating activity of the laccases

\begin{tabular}{|c|c|c|c|c|c|c|}
\hline \multirow{3}{*}{$\begin{array}{l}\text { Enzyme } \\
\text { source }\end{array}$} & \multirow{3}{*}{ Form of laccase } & \multicolumn{4}{|c|}{ Activity (nkat/mg protein) } & \multirow{3}{*}{$\begin{array}{l}\text { The oxidative } \\
\text { /demethoxylating } \\
\text { activity ratio* }\end{array}$} \\
\hline & & \multicolumn{2}{|c|}{ Oxidative } & \multicolumn{2}{|c|}{ Demethoxylating } & \\
\hline & & $\begin{array}{l}\text { ferulic } \\
\text { acid }\end{array}$ & $\begin{array}{l}\text { syringic } \\
\text { acid }\end{array}$ & $\begin{array}{l}\text { decrease } \\
\text { of }-\mathrm{OCH}_{3}\end{array}$ & $\begin{array}{l}\text { increase of } \\
\text { methanol }\end{array}$ & \\
\hline \multirow[t]{12}{*}{ A. biennis } & Constitutive & 251 & 223 & 7 & 6 & 32.0 \\
\hline & Inducible with: & & & & & \\
\hline & Björkman's & 637 & 689 & 63 & 65 & 10.9 \\
\hline & lignin & 747 & 712 & 22 & 24 & 32.4 \\
\hline & Cadmium ions & 794 & 715 & 21 & 23 & 34.0 \\
\hline & $\mathrm{H}_{2} \mathrm{O}_{2}$ & 787 & 763 & 59 & 60 & 12.9 \\
\hline & Ferulic acid & 726 & 724 & 19 & 20 & 38.1 \\
\hline & Menadione & 760 & 754 & 17 & 19 & 44.4 \\
\hline & Paraquat & 712 & 725 & 62 & 59 & 11.7 \\
\hline & Lignosulfonate & 711 & 712 & 20 & 19 & 36.6 \\
\hline & Saponins & 719 & 698 & 57 & 53 & 12.2 \\
\hline & Syringic acid & & & & & \\
\hline \multirow[t]{12}{*}{ C. unicolor } & & 928 & 807 & 25 & 28 & 32.3 \\
\hline & Constitutive & & & & & \\
\hline & Inducible with: & 1392 & 1236 & 147 & 143 & 8.4 \\
\hline & Björkman’s & 1412 & 1270 & 32 & 31 & 39.7 \\
\hline & lignin & 1407 & 1209 & 31 & 33 & 39.0 \\
\hline & Cadmium ions & 1428 & 1327 & 154 & 152 & 8.5 \\
\hline & $\mathrm{H}_{2} \mathrm{O}_{2}$ & 1395 & 1310 & 34 & 33 & 38.1 \\
\hline & Ferulic acid & 1374 & 1294 & 32 & 29 & 40.4 \\
\hline & Menadione & 1411 & 1227 & 127 & 149 & 9.7 \\
\hline & Paraquat & 1398 & 1251 & 40 & 37 & 31.3 \\
\hline & $\begin{array}{l}\text { Lignosulfonate } \\
\text { Saponins }\end{array}$ & 1401 & 1390 & 154 & 159 & 9.0 \\
\hline & Syringic acid & 245 & 217 & 8 & 7 & 27.1 \\
\hline \multicolumn{7}{|l|}{ T. versicolor } \\
\hline & Constitutive & & & & & \\
\hline & & 5179 & 5087 & 427 & 422 & 11.8 \\
\hline & Inducible with: & 5298 & 5196 & 136 & 142 & 38.2 \\
\hline & Björkman’s & 5211 & 5226 & 126 & 131 & 41.5 \\
\hline & lignin & 5311 & 5293 & 487 & 433 & 10.8 \\
\hline & Cadmium ions & 5159 & 4980 & 129 & 139 & 38.3 \\
\hline & $\mathrm{H}_{2} \mathrm{O}_{2}$ & 4994 & 5174 & 133 & 129 & 38.9 \\
\hline & Ferulic acid & 5007 & 4973 & 417 & 427 & 11.9 \\
\hline & Menadione & 5111 & 5011 & 131 & 133 & 38.3 \\
\hline & Paraquat & 5254 & 5270 & 430 & 437 & 12.3 \\
\hline & Lignosulfonate & & & & & \\
\hline & Saponins & & & & & \\
\hline & Syringic acid & & & & & \\
\hline
\end{tabular}

* With syringic acid as a substrate and decrease of $-\mathrm{OCH}_{3}$ as demethoxylating activity.

The activity was determined in the non-induced cultures and in the cultures induced with various substances. The both activities were measured with ferulic and syringic acids as the hydrogen donor (substrate). All data represent mean of triplicate measurements (sample deviations $\leq 10 \%$ ). The data refer to enriched purified laccases (see Fig. 1).

lation as the first step of lignin degradation (Leonowicz et al., 2001). Different degree of degradation activity of white-rot fungi depends on the environmental condition and fungal species with respect to lignin and other organic compounds. Such an increased activity of laccase entails the participation of the enzyme in response mechanism to external stress factors. The presence of harmful compounds at higher concentration in the media which might appear lethal for other organisms, results in induction of detoxification abilities of this fungal group by increasing their extracellular discharge of ligninolytic enzymes, such as laccase. Even though this study does not conclusively explain the molecular aspects of laccase activity as a response to various stress factors, the above sequence of reactions justifies that laccase enzyme is very important for fungal cell for its protection against to the environmental stresses. This offers extremely large possibilities for biotechnological use of white-rot fungi.

In conclusion, the experiments what we carried out have confirmed an extremely strong resistance of white-rot fungi to detrimental changes in the external environment. Concerned to separated and purified constitutive and inducible laccases, we have unequivocally 
demonstrated the bifunctionality characteristics of the enzyme proving different specificity of these forms simultaneously. The results also strongly indicated that the extracellular laccases of $A$. biennis, $C$. unicolor and $T$. versicolor induced by lignin and its derivatives demethoxylates lignin derivatives much stronger than laccases from the other inducers. The laccases, separated and purified in high yield as constitutive forms from $A$. biennis and $T$. versicolor displayed demethoxylation activity on par, whereas activity of $C$. unicolor was three times higher. In the case of this fungus there may exist a special potential to use it for bioremediation of sites contaminated with aromatic pollutants.

\section{ACKNOWLEDGMENTS}

Part of this work was carried out with the supports of the Brain Pool Scientist Invitation Program of KOFST-KOSEF(2004), the Polish Committee for Scientific Investigations (139/E-339/SPUB-M-5PR-UE/ DZ 280/200, BW/BiNoZ/4, BS/BiNoZ/4) and the Visit Research Program of KOSEF-JSPS (2005).

\section{REFERENCES}

Adler, E. and S. Hernestam 1955 Estimation of phenolic hydroxyl groups in lignin. I. Periodate oxidation of guaiacol compounds. Acta Chem. Scand., 9: 319-334

Aramayo, R. and W. E. Timberlake 1990 Sequence and molecular structure of the Aspergillus nidulans A (laccase I) gene. Nucleic Acids Res., 18: 3415-3419

Björkman, A. 1954 Isolation of lignin from finely divided wood with neutral solvents. Nature, 174: 1057-1058

Björkman, A. 1957 Lignin and carbohydrate complexes extraction from wood meal with neutral solvents. Ind. Eng. Chem., 49: 1395-1399

Bollag, J.-M. and A. Leonowicz 1984 Comparative studies of extracellular fungal laccases. Appl. Env. Microbiol., 48: 849-854

Bradford, M. M. 1976 A rapid and sensitive method for the quantisation of microgram quantities of proteins utilizing the principle of protein-dye binding. Anal. Biochem., 72: 248-254

Brauns, F. E. 1952 Methoxyl determination in lignin derivatives. The Chemistry of Lignin. Academic Press, New York, pp. $744-745$

Cho, N. S., J. Rogalski, M. Jaszek, J. Luterek, M. Wojtas-Wasilewska, E. Malarczyk, M. Fink-Boots and A. Leonowicz 1999a Effect of coniferyl alcohol addition on removal of chlorophenols from water effluents by fungal laccase. J. Wood Sci., 45: 174-178

Cho, N. S., J. M. Park, T. H. Choi, A. Matuszewska, M. Jaszek, K. Grzywnowicz, E. Malarczyk, K. Trojanowski and A. Leonowicz 1999b The effects of wood rotting fungi and laccase on destaining of dyes and KP bleaching effluent. Mokchae Konghak, 27: 72-79

Collins, P. J. and A. D. W. Dobson 1997 Regulation of laccase gene transcription in Trametes versicolor. Appl. Environ. Microbiol., 63: 3444-3450

D'Annible, A, S. R. Stazi, V. Vinciguerra, E. Di Mattia and G. G. Sermanni 1999 Characterization of immobilized laccase from Lentinula edodes and its use in olive-mill wastewater treatment. Proc. Biochem., 34: 697-706

Dittmer, J. K., N. J. Patel, S. W. Dhawale and S. S. Dhawale 1997 Production of multiple laccase isoforms by Phanerochaete chrysosporium grown under nutrient sufficiency. FEMS
Microbiol. Lett., 149: 65-70

Edens, W. A., T. Q. Goins, D. Dooley and J. M. Henson 1999 Purification and characterization of secreted laccase of Gaeumannomyces graminis var. tritici. Appl. Env. Microbiol., 65: 3071-3074

Fahraeus, G. and B. Reinhammar 1967 Large-scale production and purification of laccase from the fungus Polyporus versicolor and some properties of laccase. Acta Chem. Scand., 21: 2367-2378

Farnet, A. M., S. Tagger and J. L. Petit 1999 Effect of copper and aromatic inducers on the laccases of white-rot fungus Marasmius quercophilus. C. R. Acad. Sci. Paris, Sciences de la vie. Life Sciences, 322: 499-503

Farnet, A. M., S. Criquet, S. Tagger, G. Gil and J. L. Petit 2000 Purification, partial characterization, and reactivity with aromatic compounds of two laccases from Marasmius quercopilus strain 17. Can. J. Microbiol., 46: 189-194

Fink-Boots, M., E. Malarczyk and A. Leonowicz 1999 Increased enzymatic activities and levels of superoxide anion and phenolic compounds in cultures of Basidiomycetes after temperature stress. Acta Biotechnol., 19: 319-330

Froehner, S. C. and K.-E. Eriksson 1974 Induction of Neurospora crassa laccase with protein synthesis inhibitors. J. Bacteriol., 120: 450-457

Gianfreda, L., F. Sannino, M. T. Filazzola and A. Leonowicz 1998 Catalytic behaviour and detoxifying ability of a laccase from the fungal strain Cerrena unicolor. J. Mol. Cat., 4: 13-23

Gigi, O., I. Marbach and A. M. Mayer 1980 Induction of laccase formation in Botrytis. Phytochemistry, 19: 2273-2275

Hofer, C. and D. Shlosser 1999 Novel enzymatic oxidation of $\mathrm{Mn}^{+2}$ to $\mathrm{Mn}^{+} 3$ catalyzed by a fungal laccase. FEBS Lett., 451 : $186-190$

Ishihara, T. and M. Miyazaki 1974 Demethylation of lignin and lignin models by fungal laccase. Mokuzai Gakkaishi, 20: 39-41

Jamieson, D. J. 1995 The effect of oxidative stress on Saccharomyces cerevisiae. Redox Report, 1: 85-95

Jarosz-Wilkolazka, A., E. Malarczyk, N. S. Cho and A. Leonowicz 2001 Ligninolytic activities of selected strains of white-rot fungi in cadmium-containing environment. Proc. 3rd Internat'l Sym. For. Prod. Biosci., Chungbuk National University, Cheongju, Korea, pp. 183-192

Klonowska, A., J. L. Petit and T. Tron 2001 Enchancement of minor laccases production in the basidiomycete Marasmius quercopilus C30. FEMS Microbiol. Lett., 200: 25-30

Leonowicz, A. 1965 Badania nad rozkladaniem ligniny przez grzyb Pholiota mutabilis. Doctors Dissertation, UMCS, Lublin, pp. 45-47

Leonowicz, A. and M. Malinowska 1982 Purification of the constitutive and inducible forma of laccase of the fungus Pholiota mutabilis by affinity chromatography. Acta Biochim. Polon, 29: 219-226

Leonowicz, A., N. S. Cho, J. Luterek, A. Wilkolazka, M. Wojtas-Wasilewska, A. Matuszewska, M. Hofrichter, D. Wesenberg and J. Rogalski 2001 Fungal laccase: properties and activity on lignin. J. Basic Microbiol., 41: 183-225

Leonowicz, A., R. U. Edgehill and J.-M. Bollag 1984 The effect of $\mathrm{pH}$ on the transformation of syringic and vanillic acids by the laccase of Rhizoctonia praticola and Trametes versicolor. Arch. Microbiol., 13: 89-96

Leonowicz, A. and K. Grzywnowicz 1981 Quantitative estimation of laccase forms in some white-rot fungi using syringaldazine as a substrate. Enzyme Microbiol. Technol., 3: 55-58

Leonowicz, A., K. Grzywnowicz and M. Malinowska 1979 Oxidative and demethoxylating activity of multiple forms of laccase from Pholiota mutabilis. Acta Biochim. Polon, 26: 431-434

Leonowicz, A., T. K. Lundell, J. Rogalski and A. I. Hatakka 1991 Demethylation and reduction of veratric acid by selected white-rot fungi. Acta Microbiol. Polon, 40: 205-220

Leonowicz, A., J. Rogalski, E. Malarczyk, K. Grzywnowicz, G. Ginalska, J. Lobarzewski, S. Ohga, N. Pashenova, S. S. Lee and 
N.-S. Cho 2000 Demethoxylation of milled wood lignin and lignin related compounds by laccase from white-rot fungus, Cerrena unicolor. Mokchae Konghak, 28: 29-40

Leonowicz, A., G. Szklarz and M. Wojtas-Wasilewska 1985 The effect of fungal laccase on fractionated lignosulfonates (Peritan Na). Phytochemistry, 24: 393-396

Leonowicz, A. and J. Trojanowski 1975 Induction of new laccase form in the fungus Pleurotus ostreatus by ferulic acid. Microbios., 13: $67-174$

Leonowicz, A. and J. Trojanowski 1975 Induction of new laccase form in the fungus Pleurotus ostreatus by ferulic acid. Acta Biochim. Polon, 22: 291-295

Leonowicz, A. and J. Trojanowski 1978 Induction of laccase in Basidiomycetes. The laccase-coding messenger. Acta Biochim. Polon, 25: 147-156

Leonowicz, A., J. Trojanowski and G. Nowak 1972 Ferulic acid as the inductor of messenger RNA synthesis related to laccase formation in the wood rotting fungus Pleurotus ostreatus. Microbios., 6: 23-28

Leonowicz, A., J. Trojanowski and B. Orlicz 1978 Induction of laccase in Basidiomycetes: apparent activity of the inducible and constitutive forms of the enzyme with phenolic substrates. Acta Biochim. Polon, 25: 369-378

Mansur, M., T. Suarez and A. E. Gondalez 1998 Differential gene expression in the laccase gene family from basidiomycete I-62 (CECT 20197). Appl. Env. Microbiol., 64: 771-774

Mansur, M., T. Suarez, J. B. Fernandez-Larrea, M. A. Brizuela and A. E. Gonzalez 1997 Identification of laccase gene family in th enew lignin degrading basidiomycete (CACT 20197). Appl. Env. Microbiol., 63: 2637-2646

Manzanares, P., S. Fajardo and C. Martin 1995 Production of ligninolytic activities when treating paper pulp effluents by Trametes versicolor. J. Biotechnol., 43: 115-132

McIlvaine, T. C. 1921 A buffer solution for colorimetric comparison. J. Biol. Chem., 49: 183-186

Monteiro, M. C. and M. E. A. Carvalho 1998 Pulp bleaching using laccase from Trametes versicolor under high temperature and alkaline conditions. Appl. Biochem. Biotechnol., 70-72:
983-993

Motoda, S. 1999 Purification and characterization of polyphenol oxidase from Trametes sp. MS39401. J. Biosci. Bioeng., 87: $137-143$

Munoz, C., F. Guillen, A. T. Martinez and M. J. Martinez 1997 Induction and characterization of laccase in the ligninolytic fungus Pleurotus eryngii. Curr. Microbiol., 34: 1-5

Palmieri, G., P. Giardina, C. Bianco, B. Fontanella and G. Sanna 2000 Copper induction of laccase isoenzymes in the ligninolytic fungus Pleurotus ostreatus. Appl. Env. Microbiol., 66: 920-924

Potthast, A. T., T. Rosenau, A. L. Chen and J. S. Gratzl 1995 Selective enzymatic oxidation of aromatic methyl groups to aldehydes. J. Org. Chem., 60: 4320-4321

Rogalski, J., A. L. Dawidowicz and A. Leonowicz 1990 Purification and immobilization of extracellular laccase of the fungus Trametes versicolor. Acta Biotechnol., 10: 261-269

Salas, C., S. Lobos, J. Larrain, L. Salas, D. Cullen and R. Vicuna 1995 Properties of laccase isoenzymes produced by the basidiomycete Ceriporiopsis subvermispora. Biotechnol. Appl. Biochem., 21: 323-333

Thurston, C. F. 1994 The structure and function of fungal laccases. Microbiology, 140: 19-26

Trojanowski, J. and A. Leonowicz 1963 Investigations on the degradation of lignin by Pholiota mutabilis. Ann. Univ. M. Curie-Sklodowska, Lublin (C), 18: 441-452

Tuor, U., K. Winterhalter and A. Fiechter 1995 Enzymes of white-rot fungi involved in lignin degradation and ecological determinants for wood decay. J. Biotechnol., 41: 1-17

Vasdev, K. and R. C. Kuhad 1994 Induction of laccase production in Cythus bulleri under shaking and static culture conditions. Folia Microbiol., 39: 326-330

Wahleithner, J. A., F. Xu, K. M. Brown, E. . Golightly, T. Halker, S. Kauppinen, A. Peterson and P. Schneider 1996 The identification and characterization of four laccases from the plant pathogenic fungus Rhizoctonia solani. Curr. Genet., 29: $395-403$ 